\title{
A Review of Problem and Approaches to the University Students in Malaysia Toward Using Wearable Fitness Technology
}

\author{
Siong Hui $\operatorname{Tan}^{1^{*}}$, Dr Soon Hin $\mathrm{Hew}^{2}$, and Prof Ts Dr Tse Kian $\mathrm{Neo}^{3}$ \\ ${ }^{1}$ Creative Arts Department, Tunku Abdul Rahman University College, Kuala Lumpur, Malaysia \\ 2 Faculty of Creative Multimedia, Multimedia University, Cyberjaya, Malaysia \\ ${ }^{3}$ Faculty of Creative Multimedia, Multimedia University, Cyberjaya, Malaysia
}

\begin{abstract}
Wearable fitness technology (WFT) is a device worn physically on the human wrist to track body activity through the calculation of one's heart rate and calories burned from the number of footsteps walked. Users of WFT utilise the device for the monitoring of body fitness. As WFT devices are popularly owned, the adoptive behaviour needed further understanding. Therefore, the attempt to extend the Unified Theory of Acceptance and Use of Technology 2 (UTAUT2) with additional determinants retrieved from aesthetics appeal would further examine the use of WFT. A recent study of Malaysian University students found that the general prevalence of university students' obesity is higher than in other Asia countries. This study focuses on investigating Malaysian university students' adoptive behaviour and factors contributing to sustained use of WFT. The use of UTAUT2 with aesthetics appeal perceived the outcome of students' physical health as the significant result in relation to adoptive behaviour and sustained use of WFT. Problem confronting by the country of university students' obesity must be addressed meticulously. Shaping the future of healthy lifestyle and selfcare advocacy is essential through the assistant of technology.
\end{abstract}

\section{Introduction}

Wearable fitness technology is a digital device that connected to the Smartphone through an internet connection. The device is worn on a person's wrist, which generates data relating to the body's activity. Consumers of wearable technology predicted as healthconscious and gym-goers. Nonetheless, the recent popularity of the device also emerges among the younger generation - university students.

The rate of Malaysian obesity is in a worrying situation, and university students are

\footnotetext{
*Corresponding author: tansionghui@tarc.edu.my
} 
contributing to the rise of the obesity rate in the country. Malaysia, like other developing countries, the data generated by World Health Organisation (WHO) study, Malaysia is one of the ten physically inactive countries in Southeast Asia, with $61.4 \%$ of Malaysians age Fifteen and above were physically inactive. The obesity cases are considered high, in which $33.3 \%$ (5.4 million) were pre-obese, and 27.2\% (4.4 million) were obese (Yusoff et al., 2018). WHO defines the definition that a person with a BMI of 30 or more is considered obese; moreover, a recent study of Malaysian University students found that the general prevalence of university students' obesity is higher than in other Asia countries (Wan Mohamed Radzi et al., 2019). This alarming situation is of utmost concern by society and the government due to the negative implication of obesity in the country. Healthcare professionals estimated that one in five adults would be obese in 2025 (Maryam, 2019); this is a severe matter that needs immediate attention due to non-communicable chronic diseases such as diabetes, heart disease, arthritis and stroke, and a few others.

Many initiatives or strategies have implemented to boost awareness. These comprise healthy eating habits, educating new nutrition policy, dietary guidelines, and few others. However, it does not show significant improvement in reducing the obesity rate. Conversely, the obese episode has extended to a broader age group; even kids have the sign of overweight. Individual lifestyle is one of the most critical factors contributing to overweight, leading to obesity (Gonzalez-Campoy, 2019; Collazo-Clavell, 2019). On the flips side, lifestyle could be the factor to reduce the rate of obesity; it the practices of compliance and appropriate physical activities to retain or maintain healthy body weight. Many studies investigated the root course of overweight from a medical perspective (Jiang \& Villareal, 2019; van der Valk et al., 2019), mainly a controlling approach to obesity. Therefore, the preventive approach that looks into the obese lifestyle with the assistance of technology is lacking.

\section{Features what problem}

\subsection{Malaysian obesity and well-being}

Obesity is an issue in Malaysia; shown through research data the consecutive rise year by year. (Euromonitor, 2019) The Malaysian National Health and Morbidity Survey (NHMS) 2015 reported that 55 years old to 59 years old has the highest overweight issue in Malaysia. ("National Health \& Morbidity Survey 2015 (NHMS 2015). Vol. II: NonCommunicable Diseases, Risk Factors \& Other Health Problems; 2015," 2015) The obesity issue is associated with type II diabetes and a higher risk of developing cardiovascular disease and metabolic syndrome. (Rashid et al., 2019), (Ahmed et al., 2019) The prevalence of overweight and obesity among university student groups has risen due to the hectic lifestyle of long working hours and eating out frequently in Malaysia. (Eow et al., 2018) (Al-Naggar et al., 2013) The obesity issue among Malaysian university students will also keep increasing rapidly. Due to high sugar consumption and fewer exercisers among the Malaysian university students, obesity issue among the Malaysian university students' group can lead to health problems such as diabetes, high blood pressure and heart disease. This issue is causing the public and private finances and a heavy burden on social welfare and hospitalisations. (Lee et al., 2010)

The World Health Organization (WHO) reported that Malaysia has the highest rate of obesity among Asian countries, with $64 \%$ of male and $65 \%$ of the female population being either obese or overweight. (Kaur, 2019) Now, Malaysia is facing the critical moment of 
obesity issue among the people. It is essential to explore adolescent weight gain because they highly linked to overweight and obesity in adults; a better understanding of university student weight gain is crucial if we are to combat the rising adult obesity prevalence

\subsection{Wearable Fitness Technology}

310.4 million Wearable technology devices sold worldwide in 2017 ("Worldwide wearable device sales to grow $17 \%$ : report," 2017), whereby Malaysia, like other countries, accounted value 54.9 million. Also, Malaysia forecast sales of wearable electronics will increase year on year, for instance, 55\% from 2016 to 2021. (Euromonitor International, 2016)

Many types of research shared evidence regarding the benefit of wearable technology. It helps users monitor their health and empower self-management in health as the device provides feedback about one's body activity. (Samonte et al., 2018), (Giddens et al., 2019), (Strath \& Rowley, 2018) Recently, buyers of wearable fitness technology are not only health conscious but are aesthetic appeal to invest in adopting wearable fitness technology. (Dehghani et al., 2018). According to Chuah (Chuah et al., 2016), aesthetic this factor showed significant importance when adopting wearable fitness technology.

Adopting wearable fitness technology as health-conscious or just a trendy accessory among university students needs further understanding. Due to wearable fitness technology's benefits to users in health supervision, it is necessary to understand the factors that influence wearable fitness technology users and non-wearable fitness technology users to adopt wearable fitness technology.

\section{An extended UTAUT2 model to measure adoption of wearable fitness technology}

This research aims at synthesising commensurable theories from various research streams to analyse university students' adoption process on wearable fitness technology. Unified Theory for the Acceptance and Use of Technology 2 (UTAUT2) (Venkatesh et al., 2003), Technology Acceptance Model (TAM) (Davis, 1989) and aesthetic appeal found to apply the combination theories to explain the adoption of wearable fitness technology. (Dehghani, Kim, \& Dangelico, 2018)

The above reason decided to combine more than two classical adoptions and use theories to understand better the adoption of wearable fitness technology in university student of Malaysia. The model developed for this study will be termed the Model of Wearable Fitness Technology Adoption (MOWFTA). The following section will explain the definition of components and the origin of the components.

\section{A. MOWFTA Hypotheses Development}

This study's leading group of constructs is social influence, facilitating conditions, performance expectancy, effort expectancy, hedonic motivation, price value, and habit drawn from UTAUT2. Second, aesthetic appeal integrated into the model. Finally, the dependent variable is the intention to use wearable fitness technology.

Table 1 below explained the definitions of the selected components of the framework and concepts drawn from the reviewed theories. 
Table 1: MOWFTA construction definition

\begin{tabular}{|l|l|}
\hline Factor & Definitions \\
\hline Facilitating \\
Conditions & $\begin{array}{l}\text { The user believed that there is a support or assist them in using } \\
\text { the new technology and information system (wearable fitness } \\
\text { technology) }\end{array}$ \\
\hline $\begin{array}{l}\text { Performance } \\
\text { Expectancy }\end{array}$ & $\begin{array}{l}\text { The user who believes the new technology or information } \\
\text { system (wearable fitness technology) will benefit their job } \\
\text { performance. }\end{array}$ \\
\hline $\begin{array}{l}\text { Effort } \\
\text { Expectancy }\end{array}$ & $\begin{array}{l}\text { The ease of use in the new technology or information (wearable } \\
\text { fitness technology) }\end{array}$ \\
\hline Social Influence & $\begin{array}{l}\text { the change in user behaviour that important people believed they } \\
\text { should use the new technology or information (wearable fitness } \\
\text { technology) }\end{array}$ \\
\hline $\begin{array}{l}\text { Hedonic } \\
\text { Motivation }\end{array}$ & $\begin{array}{l}\text { The user's enjoyment from using the technology and information } \\
\text { system (wearable fitness technology) }\end{array}$ \\
\hline Price Value & $\begin{array}{l}\text { Consumers' cognitive trade-off between the perceived benefit of } \\
\text { the applications and monetary cost of using them }\end{array}$ \\
\hline Habit & $\begin{array}{l}\text { The automatically daily usage of technology and information } \\
\text { system (wearable fitness technology) in user. }\end{array}$ \\
\hline $\begin{array}{l}\text { Aesthetic } \\
\text { Appeal }\end{array}$ & $\begin{array}{l}\text { User belief that using wearable fitness technology currently rare } \\
\text { in mainstream culture distinguishes its users from the vast } \\
\text { majority }\end{array}$ \\
\hline
\end{tabular}

Based on the model above, these variables take the same place as the external variable does in Venkatesh's model, laying out the following relationships:

- Social influence has a positive influence on the behavioural intention of wearable fitness technology adoption among university students.

- Facilitating Condition has a positive influence on the behavioural intention of wearable fitness technology adoption among university students.

- Performance Expectancy has a positive influence on the behavioural intention of wearable fitness technology adoption among university students.

- Effort Expectancy has a positive influence on the behavioural intention of wearable fitness technology among university students.

- Hedonic motivation has a positive influence on the behavioural intention of wearable fitness technology adoption among university students 
- Price Value has a positive influence on the behavioural intention of wearable fitness technology adoption among university students.

- Habit has a positive influence on the behavioural intention of wearable fitness technology adoption among university students.

- Aesthetic appeal has a positive influence on the behavioural intention of wearable fitness technology adoption with university students.

\section{Conclusion}

The problem confronting the country of university students' obesity must be addressed meticulously. Shaping the future of a healthy lifestyle and self-care advocacy is essential through wearable fitness technology. The results of the study will be of great benefit to the following:

University students. This study will provide university students with a benefit means to reduce weight management and healthy physical, contribute to psychology a boost to academic achievement, give a break to de-stress through exercise, boost positive mind-set from exercise and well-being of mental state by preventing depression.

Industry. The study will also provide marketing practitioners with some guidance for young people's motivation and behaviours of use wearable fitness technology. For example, creating and utilising advertising and sponsored messages with wearable fitness technology applications will resonate with university students.

Researcher. This study is one of the first few attempts to identify expectation and enablers to promote wearable fitness technology literacy among university students.

\section{References}

Ahmed, S. S., Laila, T. R., Thamilselvam, P., \& Subramaniam, K. (2019). Knowledge of Risk Factors and Complications of Diabetes in the Indian Ethnic Population of Malaysia Undiagnosed to Have Diabetes. 8(1), 4-8. https://doi.org/10.5923/j.diabetes.20190801.02

Al-Naggar, R. A., Bobryshev, Y. V., \& Mohd Noor, N. A. B. (2013). Lifestyle practice among Malaysian university students. Asian Pacific Journal of Cancer Prevention, 14(3), 1895-1903. https://doi.org/10.7314/APJCP.2013.14.3.1895

Chuah, S. H. W., Rauschnabel, P. A., Krey, N., Nguyen, B., Ramayah, T., \& Lade, S. (2016). Wearable technologies: The role of usefulness and visibility in smartwatch adoption. Computers in Human Behavior, 65, 276-284.

https://doi.org/10.1016/j.chb.2016.07.047

Davis, F. D., Bagozzi, R. P., \& Warshaw, P. R. (1989). User Acceptance of Computer Technology: A Comparison of Two Theoretical Models. Management Science, 35(8), 9821003. https://doi.org/10.1287/mnsc.35.8.982 
Dehghani, M., Kim, K. J., \& Dangelico, R. M. (2018). Will smartwatches last? factors contributing to intention to keep using smart wearable technology. Telematics and Informatics, 35(2), 480-490. https://doi.org/10.1016/j.tele.2018.01.007

Eow, S., and, W. G.-I. J. of P. H., \& 2018, undefined. (2018). Social Media Use, Body Image, and Body Weight Status: Comparison Between University Students With and Without Disordered. Publichealthmy.Org, http://www.publichealthmy.org/ejournal/ojs2/index.php/ijphcs/article/view/537

Euromonitor International. (2016). WEARABLE ELECTRONICS IN Malaysia.

Euromonitor. (2019). Economies and Consumers Annual Data: Obese Population(BMI $30 \mathrm{~kg} / \mathrm{sq}$. m or more) in Malaysia.

Giddens, L., Gonzalez, E., \& Leidner, D. (2019). Unintended Consequences of Wearable Fitness Devices in Corporate Wellness Programs. 2017(May 1995), 4-4. https://doi.org/10.1145/3322385.3322416

Gonzalez-Campoy, J. M. (2019). Gonadal Dysfunction and Infertility in Women with Obesity. In Bariatric Endocrinology (pp. 283-291). Springer, Cham.

Jiang, B. C., \& Villareal, D. T. (2019). Therapeutic and lifestyle approaches to obesity in older persons. Current Opinion in Clinical Nutrition \& Metabolic Care, 22(1), 30-36.

Kaur, N. (2019). Malaysia and WHO Call for More Investment in Primary Health Care the 21 st Century. World Health Organisation. https://www.who.int/malaysia/news/detail/08042019-malaysia-and-who-call-for-more-investment-in-primary-health-care-the-21stcentury

Lee, P. Y., Ong, T. A., Muna, S., Syed Alwi, S. A. R., \& Kamarudin, K. (2010). Do university students have high cardiovascular risk? A pilot study from Universiti Malaysia Sarawak (UNIMAS). Malaysian Family Physician, 5(1), 41-43.

National Health \& Morbidity Survey 2015 (NHMS 2015). Vol. II: Non-Communicable Diseases, Risk Factors \& Other Health Problems; 2015. (2015). In Institute for Public Health (IPH) 2015: Vol. Volume II. http://www.moh.gov.my/moh/resources/nhmsreport2015vol2.pdf

Rashid, N. A., Nawi, A. M., \& Khadijah, S. (2019). Exploratory analysis of traditional risk factors of ischemic heart disease (IHD) among predominantly Malay Malaysian women. BMC Public Health, 19(Suppl 4), 1-8. https://doi.org/10.1186/s12889-019-6855-5

Samonte, M. J. C., Naquila, K. R. P., \& I gnacio, R. C. C. (2018). Using a Wearable Device for an Android-based Weight Management System. TENCON 2018 - 2018 IEEE Region 10 Conference, October, 1907-1912.

Strath, S. J., \& Rowley, T. W. (2018). Wearables for promoting physical activity. In Clinical Chemistry (Vol. 64, Issue 1, pp. 53-63). https://doi.org/10.1373/clinchem.2017.272369

Wan Mohamed Radzi, C., Salarzadeh Jenatabadi, H., Alanzi, A., Mokhtar, M. I., Mamat, M. Z., \& Abdullah, N. A. (2019). Analysis of Obesity among Malaysian University Students: A Combination Study with the Application of Bayesian Structural Equation 
Modelling and Pearson Correlation. International Journal of Environmental Research and Public Health, 16(3), 1-17.

Maryam Abimbola Mikail (15 May 2019), 1 in 5 adults will be obese by 2025. The New Straits Times, https://www.nst.com.my/opinion/letters/2019/05/488749/1-5-adults-willbeobese- 2025

van der Valk, E. S., van den Akker, E. L., Savas, M., Kleinendorst, L., Visser, J. A., Van Haelst, M. M., ... \& van Rossum, E. F. (2019). A comprehensive diagnostic approach to detect underlying causes of obesity in adults. Obesity Reviews, 20(6), 795-804

Venkatesh, V., Morris, M. G., Davis, G. B., \& Davis, F. D. (2003). User acceptance of information: Toward a unified view1. MIS Quarterly, 27(3), 425-478. Retrieved from https://search.proquest.com/docview/218137148? accountid $=38945$

Yusoff, N. A. M., Ganeson, S., Ismail, K. F., Juahir, H., Shahril, M. R., Lin, L. P., ... Programme, D. (2018). PHYSICAL ACTIVITY LEVEL AMONG UNDERGRADUATE STUDENTS IN TERENGGANU, MALAYSIA USING PEDOMETER. Journal of Fundamental and Applied Sciences, 512-522. https://doi.org/http://dx.doi.org/10.4314/jfas.v10i1s.36 Journal

Worldwide wearable device sales to grow $17 \%$ : report. (2017, September). The Star Online. 